\title{
Qualidade da Democracia no Brasil e Confiança nas Instituições Políticas
}

\author{
Everton Rodrigo Santos*
}

Fábio Hoffmann**

Resumo: Este trabalho analisa a acentuação do paradoxo entre a adesão ao regime democrático brasileiro e a baixa satisfaçãoe confiança institucional. $O$ apoio ao sistema político nesse trabalho é compreendido dentro da estrutura teórica eastoniana, que percebeu nas dinâmicas do apoio difuso e específico um importante ingrediente para a estabilidade do sistema político. A partir desse apontamento conceitual mostramos, através de dados temporais do Latinobarômetro, que o apoio ao regime democrático brasileiro cresceu desde quando foi iniciada essa medição para o Brasil, em 1995, enquanto que a satisfação com seu desempenho e a confiança dos brasileiros em relação às instituições centrais do modelo de democracia representativa como os partidos políticos, Congresso Nacional e Justiça tem diminuído, consistentemente, ao longo do tempo. Examinadas algumas literaturas que procuraram explicar as causas desse fenômeno, procuramos, nesse trabalho, fugir da monocausalidade, buscando enfocar a existência de outros elementos que ajudam a justificar os motivos do aumento do paradoxo existente dentro do apoio ao sistema político brasileiro e, dentre elas, a capacidade do Estado e a mudança para valores pós-materialistas. Esse trabalho aponta para a presença desses elementos em situações variadas, e muitas vezes incompletas, o que acaba por travar o desenvolvimento da qualidade da democracia brasileira.

Palavras-chave: apoio ao sistema - confiança política - capacidade do Estado qualidade da democracia.

\footnotetext{
Abstract: This paper analyzes the accentuation of the paradox between the adherence to the Brazilian democratic regime and the low institutional satisfaction and confidence. Support for the political system in this work is understood within the

* Foi Professor Visitante na Universidade Nacional de Rosário na Argentina (UNR), é Pós-Doutor, Doutor e Mestre em Ciência Política pela Universidade Federal do Rio Grande do Sul. É professor da Universidade Luterana do Brasil (ULBRA) e da Universidade FEEVALE no PPG de Diversidade e Inclusão Social.

** Mestrando do Programa de Pós-Graduação em Ciência Política da Universidade Federal de Pelotas UFPEL. Bacharel em Ciência Política pela Universidade Luterana do Brasil - ULBRA.
} 
Campos Neutrais - Revista Latino-Americana de Relações Internacionais Vol. 1 No 1, Janeiro - Abril de 2019

theoretical framework of Easton, which perceived in the dynamics of diffuse and specific support an important ingredient for the stability of the political system. From this conceptual point of view, we show, through temporal data from the Latinobarometer, that support for the Brazilian democratic regime has grown since the beginning of this measurement for Brazil in 1995, while satisfaction with its performance and the confidence of Brazilians in relation to Central institutions of the model of representative democracy such as political parties, National Congress and Justice have consistently declined over time. Having examined some literature that sought to explain the causes of this phenomenon, we sought in this work to escape monocusality, seeking to focus on the existence of other elements that help to justify the reasons for the increase of the paradox existing within the support to the Brazilian political system and, The capacity of the state and the shift to postmaterialistic values. This work points to the presence of these elements in varied and often incomplete situations, which ends up hampering the development of the qualityofBraziliandemocracy.

Keywords: support for the system - political trust - capacity of the State - quality of democracy.

\section{Introdução}

A terceira onda de democratização (HUNTINGTON, 1991; MARKOFF, 1996) que varreu os regimes autoritários no último quarto do século XXensejou uma fecunda produção acadêmica que foi balizada por uma torrente de análises procedimentalistas (HUNTINGTON, 1991; LINZ; STEPAN, 1999; PRZEWORSKI, 1989), “pactologistas" (O’DONNELL; SCHMITTER; WHITEHEAD, 1988)e,em menor quantidade, culturalistas (INGLEHART, 1993).

Incorporada a essas concepções, a transição brasileira da ditadura para a democracia é marcada pela saída estratégica de cena das Forças Armadas em um "pacto pelo alto" que, ao mesmo tempo em queafiançou a volta de um governo civil, também continuou a o depositário de sua legitimidade institucional (SANTOS,2010). Nesse contexto, o primeiro governo civil brasileiro pós-ditadura nasce sob a tutela dos militares,e destes necessitando para a sua sobrevivência e legitimidade.

Estes traços autoritários do cenário político brasileiro de transição democrática merecem atenção, pois ainda se encontram presentes naquilo que autores como Baquero (2008) denominou de caráter híbridoda cultura política 
Campos Neutrais - Revista Latino-Americana de Relações Internacionais Vol. 1 No 1, Janeiro - Abril de 2019

brasileira, ao passo que mistura elementos deavanços formais procedimentais, como uma crescente adesão ao regime, sufrágio ampliado e competição entre as elites com autoritarismo, desconfiança institucional, alta desigualdade sócio-econômica e baixo empoderamento individual e social.

Esse fenômeno está longe de ser exclusividade brasileira. Pippa Norris (1999), dentre seus achados, encontrou o que passou a denominar de“cidadãos críticos”, ou seja, indivíduos dotados de alta capacidade cognitiva sobre o campo da política, com fortes aspirações democráticas, mais expostos e sensíveis ao noticiário político negativo, que tendiam a se comportar de maneira mais crítica no apoio ao sistema político, principalmente quanto a confiança nas instituições políticas.Catterberg e Moreno (2005), comparando a confiança e o desempenho institucional em democracias consolidadas e em jovens democracias, chegaram à conclusão de que esse fenômeno em países Latino-americanos e do Leste Europeu era causado por uma pós-lua de mel com a transição para a democracia.

Este trabalho, assim como Lipset (1967), entende que a legitimidade de um sistema político dependeda capacidade dele de construir e manter a crença de que suas Instituições políticas são os principais canais de solução dos problemas da sociedade e que sua legitimidade é valiosa para qualquer regime, "mas crucial para as democracias" (INGLEHART, 2002, p. 148). O problema apresentado, portanto, é o de investigar o paradoxo entre crescente adesão ao regime e a baixa satisfação e confiança institucional. Sua hipótese central sugere que a capacidade do Estado de garantir a Lei e a qualidade da burocracia, aliadas a uma mudança, ainda que incompleta, dos valores materialistas para pós-materialistas explicam, em parte, a fragilidade no apoio em sua dimensão mais específica.

Para sustentar nossas hipóteses, lançamos mão de dados das séries temporais do consórcio Latinobarômetroem duas situações: na primeira, o utilizamos para apontar a crescente distância entre a adesão ao regime e a satisfação e confiança em suas instituições políticas; já na segunda montamos três gráficos nos quais pretendemos justificar e analisar a capacidade do Estado brasileiro em duas dimensões. Para analisar e apontar algumas mudanças dos valores materialistas para pós-materialistas nos valemos dos dados, tambémde séries temporais, do World Values Survey. 
Campos Neutrais - Revista Latino-Americana de Relações Internacionais Vol. 1 No 1, Janeiro - Abril de 2019

\section{A Multidimensionalidade do Apoio Político}

A democracia brasileiraavança para além de seus trinta anos, e isso é traduzido de modo experimental através de inúmeras eleições livres, amplas e idôneasrealizadas; há umamplo leque de partidos políticos para representar as clivagens sociais e os grupos de interesse; a oposição política tem seu lugar institucionalizado para a prática da contestação; existe liberdade de expressão e fontes alternativas de informação para o cidadão, em outras palavras, podemos dizer que já foram institucionalizados os procedimentos necessários para a consolidação da poliarquia (DAHL, 2012).

Apesar de estabelecidos os procedimentos necessários para o funcionamento da democracia, seus resultados, não tem conseguido atender as expectativas e demandas da sociedade. Moisés (2013, p.31), coloca a questão de a democracia brasileira conviver indefinidamente com um cenário de contínuo e crescente descrédito por parte de seus cidadãos ao avaliarem com baixos níveis de confiança a suas instituições políticas centrais. Se isso acontece, as instituições políticas estariam prejudicadas em sua capacidade de coordenar a sociedade na busca de cooperação para a resolução dos seus principais problemas.

Na busca de uma melhor compreensão ao analisar em que medida se encontra institucionalizada a democracia brasileira, nos valemos da importante contribuição de David Easton (1968), que com base em seus conceitos deapoio difuso e específico, ampliou o horizonte teórico sobre as bases da legitimidade de um sistema político. De acordo com Easton,“onde tal apoio ameaça cair abaixo de um índice mínimo, independentemente da causa, o regime precisa providenciar mecanismos para reestabelecer o apoio vacilante ou seus dias estarão contados” (EASTON, 1968, p.168).

No entanto, como chama a atenção Norris (2011), não podemos deixar de lado o caráter multidimensional do apoio ao sistema, apontando para a existência de pelo menos cinco níveis deles: sentimento de identidade e orgulho nacional; adesão ao regime enquanto princípios e valores; avaliação e satisfação com seu desempenho; confiança em suas instituições; e confiança em líderes políticos. Quanto maior é o apoio em cada uma dessas dimensões, maior será a legitimidade do sistema, do regime, das instituições, do governo e de seus líderes. Esse apoio, no entanto, de acordo com alguns autores das correntes de estudos da cultura política (FUKUYAMA, 1995; PUTNAM, 2000; INGLEHART \& WELZEL, 2009; NORRIS, 1999) é 
Campos Neutrais - Revista Latino-Americana de Relações Internacionais

Vol. 1 No 1, Janeiro - Abril de 2019

preenchido por meio de valores e virtudes sociais, crenças em formas específicas de convivência em comunidade que ajudam a consolidar e promover o sistema político e a democracia como seu regime.

Figura 1

Dimensões do Apoio*

\begin{tabular}{|c|} 
Apoio ao sistema \\
Sentimento de patriotismo e orgulho nacional \\
Adesão ao regime \\
Apoio ao valores democráticos \\
Satisfação com o regime \\
Satisfação com o funcionamento da democracia e politicas públicas \\
Confiança nos partidos politicos, Congresso Nacional, Estado, Justiça \\
Apoìio às lideranças \\
Avaliação positiva e apoio às lideranças politicas \\
\hline
\end{tabular}

Fonte:Baseado na obra de Pippa Norris, Democratic Deficits: crtical citizens revisited (2011).

*Detalha as cinco dimensões do apoio político, do mais difuso ao mais específico.

\section{Capital Social e Confiança Política}

Tanto em países que se democratizaram na terceira onda, como é o caso do Brasil, quanto nas democracias já consolidadas, como os EUA, o fenômeno da baixa confiança interpessoal e em instituições políticas tem aparecido em análises comparadas como uma variável comum (PUTNAM, 2000; NORRIS, 1999; CATTERBERG \& MORENO, 2006; PARK \&SHIN, 2010; BAQUERO, 2008; MOISÉS, 2013).

A seminal obra The Civic Culture (1963) de Gabriel Almond e Sidney Verba foi a primeira a procurar, de modo sistemático, uma relação entre cultura e democracia. Os autores encontraram nas relações entre "orientações do sujeito" e "orientações do participante" os elementos necessários ao desenvolvimento e consolidação da democracia. Castro (2014), no entanto, aponta quenão se pode cair no erro da "armadilha da cultura cívica”, que estabelece que a democracia só poderia existir em sociedades com uma cultura cívica que tivessem essas orientações. Segundo o autor, cair nesse tipo de armadilha, além de aceitar um modelo ideal de sociedade, mais 
Campos Neutrais - Revista Latino-Americana de Relações Internacionais Vol. 1 No 1, Janeiro - Abril de 2019

grave ainda seria "implicitamente defender a impossibilidade de existência de democracias em outras sociedades" (CASTRO, 2014, p.33).

Robert Putnam (1993) em um robusto estudo sobre o processo de descentralização do governo na Itália na década de setenta chegou a conclusões importantes sobre o impacto da cultura para o desenvolvimento econômico, social e institucional. Para o autor maiores estoques de confiança interpessoal, reciprocidade e cooperação explicavam o melhor desempenho econômico, social e institucional da região norte, enquanto que sua insuficiência na região sul, a atrasava e criava as condições para o surgimento de um poder paralelo ao do Estado, a máfia. $\mathrm{Na}$ ausência de um estoque de confiança social necessária para o cumprimento dos contratos sociais, a presença da máfia surgia como um garantidor da Bona Fide ${ }^{1}$ para o desenvolvimento.

Estudiosos do capital social, entre eles Baquero (2008) e Santos (2013) tem apontado resultados de pesquisas aplicadas em diferentes regiões brasileiras comprovando a tese de que quanto maior a confiança interpessoal, a reciprocidade e a cooperação social, melhores serão os resultados das políticas públicas e desenvolvimento econômico e social. Nessa orientação, o estudo feito por Pase e Santos (2008) do impacto positivodo capital social nas diferentes taxas de desenvolvimento nos Coredes gaúchos Nordeste e do Coredes Vale do Rio dos Sinos explicam, como a melhor colocação para o segundo e o maior desenvolvimentopara o primeiro, suas melhores posições no ranking do Idese ${ }^{2}$.

Este trabalho entende a centralidade da questão da cultura política para um preenchimento qualitativo da democracia procedimental, nesse sentido, portanto, elementos como confiança interpessoal, solidariedade, reciprocidade e cooperação social respondem conjuntamente a uma melhor capacidade de coordenação da sociedade para a expansão das liberdades substantivas humanas (SEN, 2000). Além de favorecer a expansão das liberdades substantivas, estes elementos facilitam também resultados positivos de políticas públicas e a consequente promoção do desenvolvimento da confiança institucional, tema que tem atraído a atenção de

\footnotetext{
${ }^{1}$ Boa fé.

${ }^{2} \mathrm{O}$ Índice de Desenvolvimento Socioeconômico (Idese) é calculado pela Fundação de Economia e Estatística Siegfried Emanuel Heuser (FEE) considerando a situação socioeconômica dos municípios gaúchos quanto à educação, à renda e à saúde englobando aspectos quantitativos e qualitativos. Para mais informações acesse: http://www.fee.rs.gov.br/indicadores/indice-de-desenvolvimentosocioeconomico/.
} 
Campos Neutrais - Revista Latino-Americana de Relações Internacionais Vol. 1 No 1, Janeiro - Abril de 2019

pesquisadores devido aos índices de confiança em instituições políticas em democracias contemporâneas terem despencado na última década do século $\mathrm{XX}$ e início do século XXI.

A questão da confiança está ligada a segurança de procedimento ou o prévio conhecimento as respostas dadas pelos atores com os quais se interage. No entanto, diferentemente da confiança interpessoal ou social onde se "pode esperar reciprocidade, indiferença ou hostilidade” (MOISÉS, 2010, p.53), a confiança política diz respeito ao funcionamento de regras, normas e estruturas que condicionam o funcionamento das instituições e cujos efeitos recaem sobre o cidadão, "em outras palavras, a confiança política dos cidadãos em instituições dependeria da coerência delas com a sua autojustificação normativa” (MOISÉS, 2013, p. 44).

A confiança política tem centralizado os debates a partir de sua característica de alimentar a capacidade de cooperação, recurso importante do qual o Estado moderno não pode deixar de lançar mão para realizar, com eficácia, a sua tarefa central que consiste em coordenar as complexas sociedades contemporâneas. Dessa forma, como afirma Offe (1999), diante da acentuação do processo de globalização, o Estado já não mais como o agente exclusivo e articulador dos processos políticos públicos, fragilizado, necessita cada vez mais se apoiar na coordenação e cooperação social, e para isso precisa engendrar a confiança de que suas instituições são os meios mais eficazes para programar e implantar suas políticas públicas.

A baixa confiança em instituições brasileiras é um fenômeno que vem se agravando nas últimas duas décadas. Catterberg e Moreno (2006) argumentam que países que fizeram a transição recente para a democracia, como é o caso brasileiro, estariam passando por um momento de “pós-lua de mel” com o regime. A análise de Ribeiro (2011) também seguiu esse caminho, para o autor teriam sido geradas enormes expectativas de que o regime democrático resolveria muitos dos problemas que o anterior não foi capaz de resolver, e uma vez que essas expectativas não foram atendidas, os sintomas mais recorrentes seriam a frustração e a desilusão com a democracia, tendo a baixa confiança em suas instituições como o reflexo desse sintoma.

É importante ressaltar que a argumentação teórica do “pós-lua de mel” surgiu como alternativa a tese dos cidadãos críticos de Norris (1999), para nações que, segundo os autores, ainda não possuíam os requisitos necessários para se gerar cidadãos dotados de valores de autoexpressão e emancipação humana. Em 
Campos Neutrais - Revista Latino-Americana de Relações Internacionais Vol. 1 No 1, Janeiro - Abril de 2019

democracias consolidadas a baixa confiança institucional pode agir como um ativador natural potencial da capacidade de renovação e resiliência das instituições e lideranças políticas, enquanto que em jovens democracias, como é o caso da brasileira, ela age mais como um agente que desestabiliza e trava o processo decisório,além de minar, consequentemente, a legitimidade institucional, contaminando, dessa forma, o avanço da qualidade do regime.

\section{Valores em Mudança}

No início da década de setenta, Ronald Inglehart ao publicar The Silent Revolution in Erope (1971) levantou originalmente a tese de que estava ocorrendo uma mudança importante nos valores das populações de países da Europa Ocidental do pós-Segunda Guerra Mundial. Esses valores estavam transitando entre o que ele denominava de valores materialistas para valores pós-materialistas, ou seja, valores que buscavam em primeiro lugar uma segurança material substancial estavam cedendo espaço para valores que, por sua vez, buscavam a emancipação e a autoexpressão humana como manifestações de vida.

As hipóteses de Inglehart sugeriam uma reformulação da teoria da modernização de Lipset (1967) uma vez que indicava que o apenas o crescimento econômico não levava à democracia, mas sim que o crescimento e desenvolvimento econômico levavam a uma maior segurança material geracional, enquanto plantava a semente nas gerações futuras por maior demanda de participação e expressão, esses sim, valores que seriam compatíveis e demandavam a democracia como regime de governo.

Pippa Norris (2011) destacou que os valores pós-materialistas orientam os cidadãos para posturas mais críticas no apoio ao regime. Sua tese dos cidadãos críticos(1999) destacou a presença de um cidadão cada vez mais crítico na hora de avaliar o regime democrático. Este cidadão ao mesmo tempo em que adere a democracia em conjunto com os respectivos valores carregados por esta, em sua dimensão mais difusa, avalia mal seu desempenho e destina uma baixa confiança em suas instituições.

Em relação ao Brasil, no que tange ao controverso debate sobre a validade metodológica e a presença dos valores pós-materialistas (RIBEIRO, 2007),Rachel Meneguello ressaltou que esse fenômeno se explicaria pelo aparecimento do que denominou de "combinações incompletas" (MENEGUELLO, 2010), ou seja, um 
Campos Neutrais - Revista Latino-Americana de Relações Internacionais

Vol. 1 No 1, Janeiro - Abril de 2019

cenário paradoxal onde há uma crescente e consistente adesão avalores da democracia que vem acompanhadoconcomitantementede baixos índices de satisfação e avaliação de seu funcionamento, além da baixa confiança nas instituições políticas.

Longe de expressarum contexto de condição material resolvida, grande parcela da sociedade brasileira apresenta níveis baixos de escolaridade 3 e taxas preocupantes de analfabetismo funcional 4 , possui ainda acentuada concentração de renda 5 e transita entre um Estado que oferta serviços públicos de baixa qualidade e é insuficiente garantidor do Estado de direito. Os cidadãos brasileiros, em perspectiva ampliada, estão cada vez mais inseridos no processo de globalização, e de maneira incongruente absorvem os diversos valores trazidos a reboque desse processo.

Dessa forma, a baixa capacidade do Estado brasileiro se alia a imersão do cidadão brasileiro em valores cada vez mais espelhados pelo processo de globalização, o que acaba por orienta-lo em uma perspectiva cada vez mais exigente em demanda por responsividade do regime, ou seja, das suas instituições e de seus serviços. Mesmo não estando em uma condição de pós-materialidade, esse cidadão passa a pressionar e exigir maior qualidade do sistema político em todas as suas dimensões.

\section{Capacidade do Estado Brasileiro}

A capacidade do Estado, neste trabalho, é analisada como um importante elemento para compreender a democratização, consolidação e qualidade do regime em diferentes países. Tilly (2013) chama a atenção para o fato de que nenhuma democracia pode funcionar se o Estado não possui a capacidade de programar, implementar e supervisionar as decisões realizadas através dos processos políticos públicos.

Pippa Norris (2012) destacou que a capacidade do Estado está diretamente ligada à qualidade da democracia, e a distinguiu baseada em duas dimensões weberianas: a primeira é o Estado como detentor do monopólio legítimo da violência e sua competência para garantir a segurança e Estado de direito (rule of law),

\footnotetext{
3Segundo a Pesquisa Nacional por Amostra de Domicílio - Pnad (2014) do Instituto Brasileiro de Geografia e Estatística (IBGE), apesar de decrescente, taxa de analfabetismo entre os que têm 15 anos ou mais, está em $8,3 \%$ de analfabetos, o que representa 13,2 milhões de pessoas.

4A taxa de analfabetismo funcional (pessoas com 15 anos ou mais, com menos de 4 anos de estudo), segundo a Pnad (2014) é de 17,6\%.

$5 \mathrm{O}$ coeficiente de Gini possui variação entre o e 1 , quanto mais próximo de 1 mais concentrada é a renda do país ou região. Segundo dados do Banco Mundial de 2013, o índice de Gini para o Brasil é de $52,9 \%$.
} 
Campos Neutrais - Revista Latino-Americana de Relações Internacionais Vol. 1 No 1, Janeiro - Abril de 2019

garantindo o império da lei (enforcement of law); a segunda é a qualidade do corpo burocrático para entregar bons serviços, a partir de características como meritocracia, plano de carreira avançado, independência das pressões que a conjuntura política fomenta, e controle da corrupção.

De acordo com Fukuyama (2015), existe uma incapacidade de institucionalização do Estado em democracias da terceira onda, onde estas, por sua vez, não têm conseguido atender a crescente demanda popular por accountability ${ }^{6}$ democrática. No caso brasileiro há uma convergência, em nosso entender, de que as análises dessas dimensões não podem ser dissociadas da questão cultural, onde os resíduos de um passado colonial escravocrata e uma religião católica centralizadora tiveram papéis centrais na configuração do tipo de cultura política presente no país. Para Inglehart e Welzel (2009, p. 92) "a cultura de uma sociedade reflete toda a sua herança histórica". Portanto, e se filiando a essa linha de análise, faz toda a diferença no futuro de uma sociedade a maneira como ela se organizou econômica, social e politicamente no passado e se organiza no presente.

Embora este trabalho não pretenda cair na armadilha do determinismo cultural, é importante apontar para a persistência de traços fortes de personalismo, clientelismo e (neo) patrimonialismo presentes na cultura política brasileira (FAORO, 2012; SCHWARTZMAN, 1982). Uma vez associada às tentativas de modernização econômica, política e social, esse tipo de cultura política, configura o que Baquero (2008) denominou de cultura política híbrida, na medida em que mistura avanços nas dimensões formais procedimentais que, no entanto, não conseguem eliminar traços deletérios que retardam o desenvolvimento da qualidade da democracia, principalmente em relação à sua dimensão social.

Castro (2014) incorporou à sua análise variáveis de natureza econômica e social, e chegou ao entendimento de que o tipo de cultura política formada no Brasil é fragmentária, ou seja, diante de um contexto de enorme desigualdade, as pessoas são incapazes de discernir que seus problemas individuais se confundem com os problemas sociais, ao mesmo tempo em que não compreendem de que forma os

\footnotetext{
${ }^{6} \mathrm{O}$ conceito de accountability usado neste trabalho é o delimitado por Schedler (1999, p. 17 apud MORLINO, 2010) que, segundo o autor, possui três características principais: informação, justificação e punição/compensação. Primeiramente deve se receber a informação sobre o ato ou ação política, a partir disso é gerada uma reflexão sobre essa informação, finalizando com uma compensação de apoio ou punição com o não apoio.
} 
Campos Neutrais - Revista Latino-Americana de Relações Internacionais Vol. 1 No 1, Janeiro - Abril de 2019

fenômenos políticos e econômicos os afetam direta e indiretamente, e acabam transformando suas realidades cotidianas.

Para mensurar essa dimensão montamos, a partir de dados temporais do Latinobarômetro para o Brasil, cinco gráficos: confiança na Justiça (5), avaliação do judiciário (6), insatisfação com os serviços públicos - dimensão objetiva (7), insatisfação com os serviços públicos - dimensão subjetiva (8) e percepção da corrupção e transparência do governo (9). Estes gráficos esperam contemplar elementos que representem as dimensões que tratam da percepção do brasileiro sob o respeito às leis e Estado de direito, satisfação com os serviços públicos, percepção da corrupção e transparência do Governo.

\section{Qualidade da Democracia}

Definir o conceito de qualidade da democracia não é uma tarefa simples. Neste trabalho, é bom relembrar a caracterização que a democracia sofreu ao longo do tempo, que avançou de termos minimalistas como voto livre e competição livre (SCHUMPETER, 1953), para aspectos procedimentalistas como competição, participação, direito de voto, eleições livres e idôneas, fontes alternativas de informação e liberdade de expressão (DAHL, 2012). A qualidade da democracia também é um fenômeno multidimensional, pois decorre principalmente da complexidade de envolver e avançar nas questões minimalistas e procedimentalistas da democracia para aspectos subjetivos e substantivos ligados à sua qualidade, ou seja, seus resultados, que neste trabalho é entendido como a ampliação do apoio ao sistema político brasileiro ao longo da extensão de toda a sua dimensão.

Nesse caminho, Diamond e Morlino (2005) destacaram que a qualidade da democracia pode ser analisada a partir de três diferentes ângulos: dos procedimentos, dos conteúdos e dos seus resultados. Quando falamos de procedimentos, nos referimos ao Estado de direito, participação e competição, accountability vertical e horizontal; já em relação aos conteúdos, eles estão ligados às dimensões mais substantivas como o respeito às liberdades civis e políticas, a accountability política, ou seja, a sensibilidade para a responsividade da elite política; quanto aos resultados estamos tratando diretamente da accountability social, a partir da condição da sociedade de apurar e fazer um julgamento sobre as políticas públicas, o desempenho do governo e a confiança nas instituições. 
Campos Neutrais - Revista Latino-Americana de Relações Internacionais Vol. 1 No 1, Janeiro - Abril de 2019

Como exposto nos dados dos gráficos anteriores, as dimensões relacionadas aos procedimentos e conteúdos não encontram críticas mais agudas, uma vez que no Brasil há eleições livres, periódicas e idôneas, com grande participação (o voto é obrigatório) e com grande potencial de contestação pública. Segundo dados da Freedom House7, o Brasil está classificado como "livre", ou seja, existe respeito aos direitos políticos e às liberdades civis. No entanto, é quanto aos seus resultados que a democracia brasileira revela sua fragilidade.

Em um importante estudo sobre o sistema judiciário brasileiro, Fabíola Brigante Del Porto $^{8}$ destacou que na percepção dos brasileiros não há equidade, universalidade nem imparcialidade no tratamento das leis no país. Meneguello (2013), estudando as bases do apoio ao regime democrático no Brasil, verificou que os serviços públicos são muito mal avaliados, principalmente serviços como transporte público, saúde, segurança pública e educação, e ainda mais, os brasileiros tem uma percepção de corrupção generalizada, que não se restringe ao setor público, mas que afeta, de forma decisiva, também o setor privado.

No cálculo feito a partir da accountability social, os brasileiros não estão satisfeitos com o funcionamento da democracia, e desconfiam cada vez mais das instituições centrais de representação como os Partidos Políticos e o Congresso Nacional. Dessa forma, nos confinamos cada vez mais a um modelo de democracia inercial (BAQUERO, 2013), dada a capacidade de desenvolvimento e avanço da sua legitimidade no sentido formal, mas quando vamos mensurar entre os brasileiros seus resultados, no sentido de avanço social, ela demonstra fragilidade na legitimidade, pois não tem conseguido responder, com eficácia, aos anseios e demandas da população por serviços públicos de qualidade.

Esse parece ser o dilema central de muitas democracias da terceira onda, altos índices de adesão ao regime democrático caminhando lado a lado com baixos índices de satisfação com o desempenho do regime e baixa confiança institucional, onde as

7A FreedomHouse classifica os países baseada em notas de 1 a 7, como "livres" (1>3), "parcialmente livres" (2>5) e "não livres" (5>7) tendo como base de sustentação para esse julgamento, grosso modo, duas variáveis: direitos políticos e liberdades civis. No entanto, para classificar se um país é uma democracia eleitoral ela busca elementos procedimentais como voto universal, nível de competição entre as elites políticas, acesso aos meios de comunicação alternativos, etc. Em 2008 o Brasil era classificado como "parcialmente livre", com notas entre 3 para direitos políticos e 4 para liberdades civis. Já em 2016 ele é denominado "livre", com nota 2 para ambos os quesitos.

${ }^{8}$ As análises de Fabíola Brigante Del Porto estão em seu artigo "A Avaliação do Judiciário e o Acesso à Cidadania na Visão dos Brasileiros" que constitui um capítulo do livro "A desconfiança Política e Seus Impactos na Qualidade da Democracia”, publicado por José Álvaro Moisés e Rachel Meneguello (2013). 
Campos Neutrais - Revista Latino-Americana de Relações Internacionais

Vol. 1 No 1, Janeiro - Abril de 2019

instituições mais afetadas são justamente aquelas compostas da prerrogativa central deabsorvere canalizar os anseios e demandas da sociedade, e achar as melhores respostas e soluções para os seus mais diferentes problemas.

\section{Análise dos gráficos}

Desde a redemocratização, a adesão ao regime cresceu consideravelmente desde o início das medições do Consórcio Latinobarômetro em 1995. As respostas para a chamada "hipótese de Churchill”mostravam, em seu início (1995 até 2005), índices significativos para aqueles que preferiam um regime autoritário a um democrático e para aqueles que eram indiferentes quanto à escolha do regime. Esse tipo de pergunta é conveniente na medida em que grande parcela da população adulta experimentou o regime autoritário anterior e está nas condições de poder avaliar a jovem democracia instalada. De 2005 até 2015 os que preferem um regime democrático a um autoritário chegou a54\%, no entanto, este índice caiu para o menor patamar de sua história: em 2016 são 32\% que consideram o regime democrático a melhor forma de governo frente às demais. O que cresceu foi o índice dos chamados "ambivalentes", ou seja, aqueles para quem tanto faz um regime autoritário ou um de natureza democrática, que subiu de 16\% em 2015 para 42\% em 2016. Observe os dadosdo gráfico 1 abaixo:

\section{Gráfico1}

Apoio à democracia*

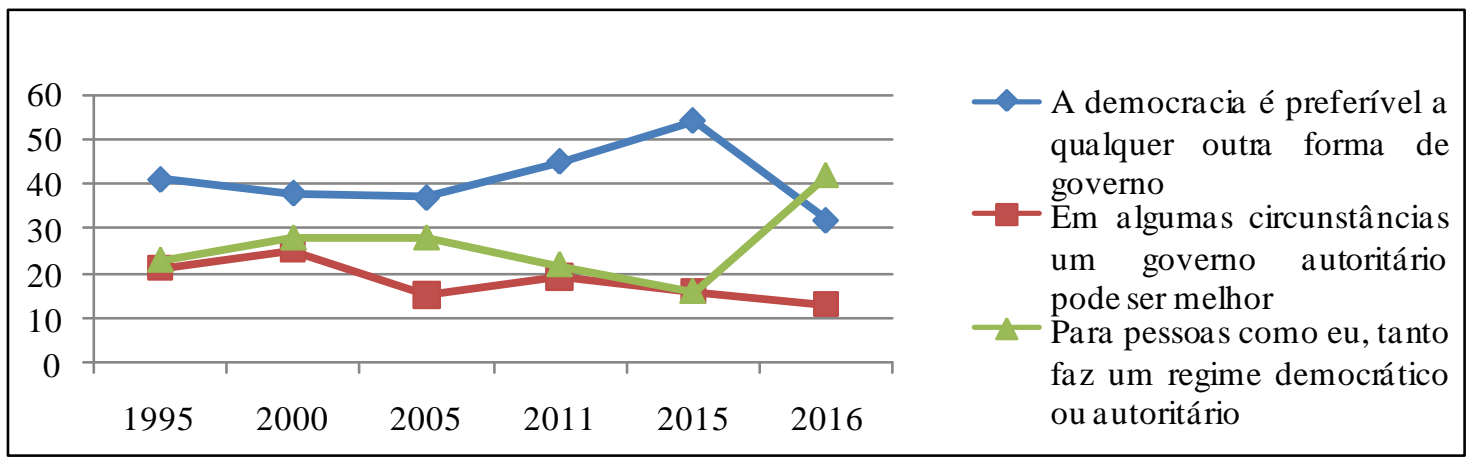

Fonte: Latinobarômetro (surveys 1995, 2000, 2005, 2011, 2015 e 2016).

*O gráfico mostra a direção das respostas em relação ao apoio à democracia, onde os dados da coluna expressam a porcentagem e, as linhas, a série temporal. Neste gráfico foram ignoradas duas possíveis respostas ao questionário "não sabe" e "não responderam" por não acarretarem maiores implicâncias à análise dos dados.

O Gráfico 2, com dados do Latinobarômetro da série temporal chegando a 2016, a afirmativa “A democracia pode ter problemas, mas é o melhor sistema de 
Campos Neutrais - Revista Latino-Americana de Relações Internacionais Vol. 1 No 1, Janeiro - Abril de 2019

governo" mostra resultados importantes que ressaltam o avanço da adesão à democracia como ideal e princípios de governo, pois 70\% dos brasileiros preferem o regime democrático como sistema de governo.

\section{Gráfico2}

A democracia pode ter problemas, mas é o melhor sistema de governo*

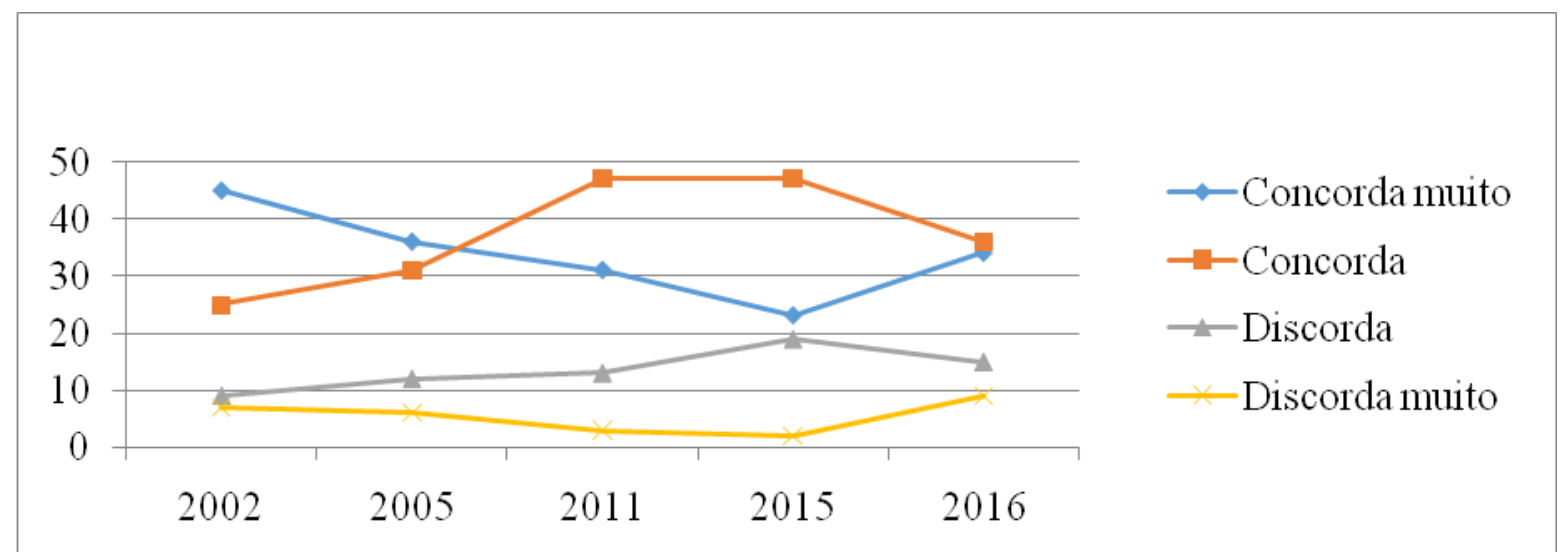

Fonte: Latinobarômetro (surveys 2002, 2005, 2011, 2015 e 2016).

*O gráfico mostra a direção das respostas em relação à chamada "hipótese de Churchill", onde os dados da coluna expressam a porcentagem e, as linhas, a série temporal. Foram ignoradas, na construção desse gráfico, duas possíveis respostas ao questionário, "não sabe" e "não responderam", por não acarretarem em maiores implicações à análise dos dados.

Já o gráfico 3 revela aspectos ligados à satisfação quanto ao funcionamento do regime democrático na série temporal, chegando à 2016. Chamamos a atenção para os números que mostram que, em 2016, apenas 10\% dos entrevistados responderam estarem satisfeitos com o funcionamento da democracia, enquanto que os insatisfeitos chegam a $87 \%$. 
Campos Neutrais - Revista Latino-Americana de Relações Internacionais

Vol. 1 No 1, Janeiro - Abril de 2019

Gráfico3

Satisfação com o funcionamento da democracia*

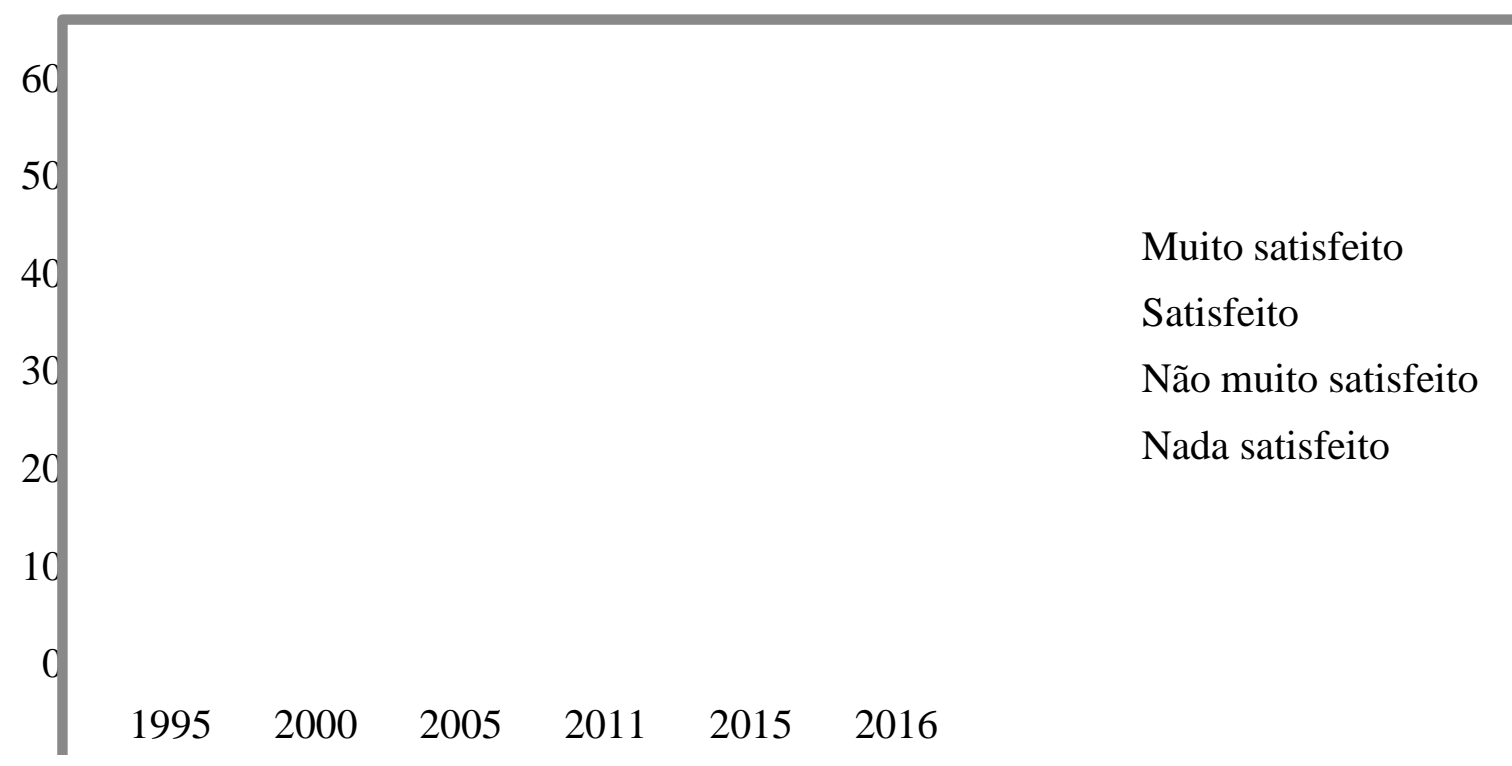

Fonte: Latinobarômetro (surveys 1995, 2000, 2005, 2011 e 2015).

*O gráfico mostra a direção das respostas em relação à satisfação com a democracia, onde os dados da coluna expressam a porcentagem e, as linhas, a série temporal. Neste gráfico foram ignoradas duas possíveis respostas ao questionário "não sabe" e "não responderam" por não acarretarem maiores implicâncias à análise dos dados.

No gráfico 4, com dados do Latinobarômetro da série temporal, de 1995 a 2016, os Partidos Políticos e Congresso Nacional aparecem com os mais baixos índices de confiança por parte dos brasileiros chegando a apenas 6\% e $13 \%$, respectivamente. Governo Federal, Estado e a Justiça também apresentam índices decrescentes, à exceção da Justiça que subiu de 32\% em 2015 para 39\% em 2016, melhora que pode ser explicada em grande medida pela percepção do cidadão das ações como a Lava Jato e outras no combate à corrupção. À exceção da Justiça, todas as demais instituições apresentam quedas consistentes e persistentes desde que a medição iniciou em 1995. 


\section{Gráfico 4}

Índice de confiança*

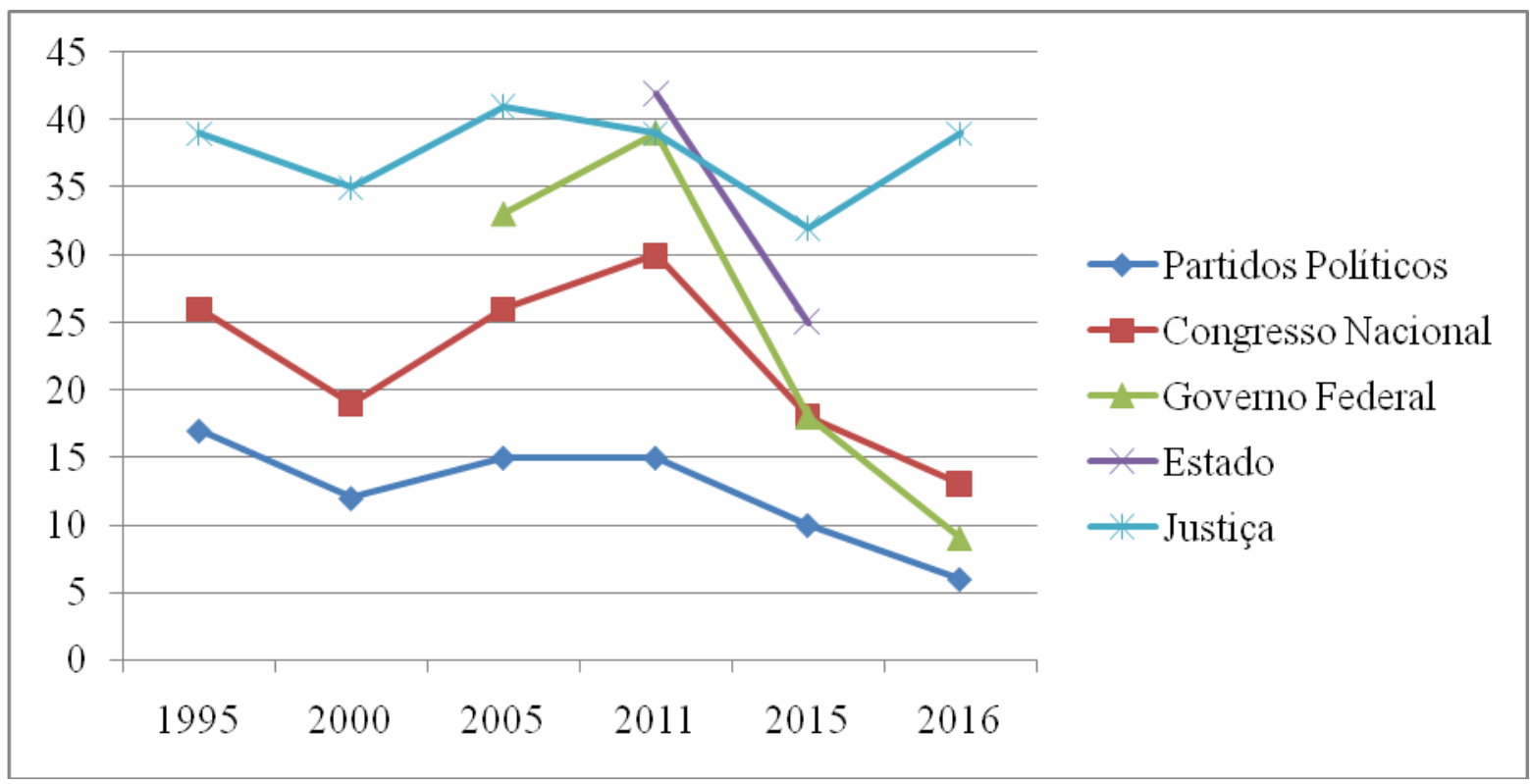

Fonte: Latinobarômetro (surveys de 1995, 2000, 2005, 2011, 2015 e 2016).

*Para a construção do gráfico recodificamos algumas medidas, agrupando as opções "confia muito" e "confia", onde os dados apresentam apenas os resultados a essas duas respostas, e expressam na coluna sua porcentagem, e nas linhas, a série temporal.

O cidadão brasileiro, de acordo com os dados das pesquisas, não acredita que as instituições vêm cumprindo com suas funções normativas. Os casos mais críticos se apresentam quando analisamos duas das instituições centrais para a democracia: Partidos Políticos e Congresso Nacional. Nessa direção, os trabalhos de Moisés e Carneiro (2008) apresentaram resultados em que os brasileiros, mais que nenhum outro povo latino-americano, estão dispostos a aceitar um arranjo institucional que não contemplem essas duas instituições, que são centrais nos modelos de democracia liberal.

No gráfico 5, percebemos que a confiança na Justiça, depois de uma queda constante, voltou a subir. Em 2015, 32\% diziam confiar na Justiça, já em 2016 esse índice subiu para 39\%.Enquanto o índicedos que não confiam declinou de $63 \% \mathrm{em}$ 2015 para 58\% em 2016. Já no gráfico 6, sobre a avaliação do funcionamento do Poder Judiciário, em 2006, 53\% avaliavam como "bem" e "muito bem”, em 2015 esse índice caiu para $29 \%$, ficando em $59 \%$ os entendem que ele funciona "mal" e "muito mal". 


\section{Gráfico 5}

Confiança na justiça*

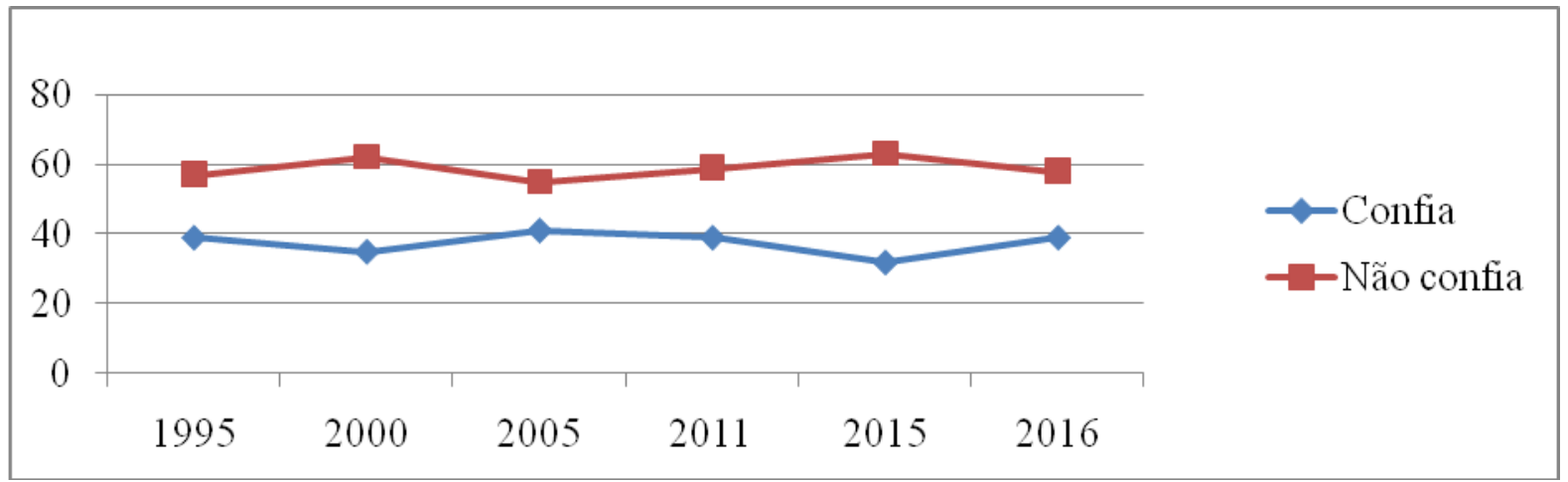

Fonte: Latinobarômetro(surveys 1995, 2000, 2005, 2011, 2015 e 2016).

*O gráfico mostra a direção das respostas em relação à confiança na Justiça. Foram somados os dados das respostas "confia muito" com "confia" e "confia pouco" com "não confia" e criado apenas dois vetores.

\section{Gráfico 6}

Avaliação do poder judiciário*

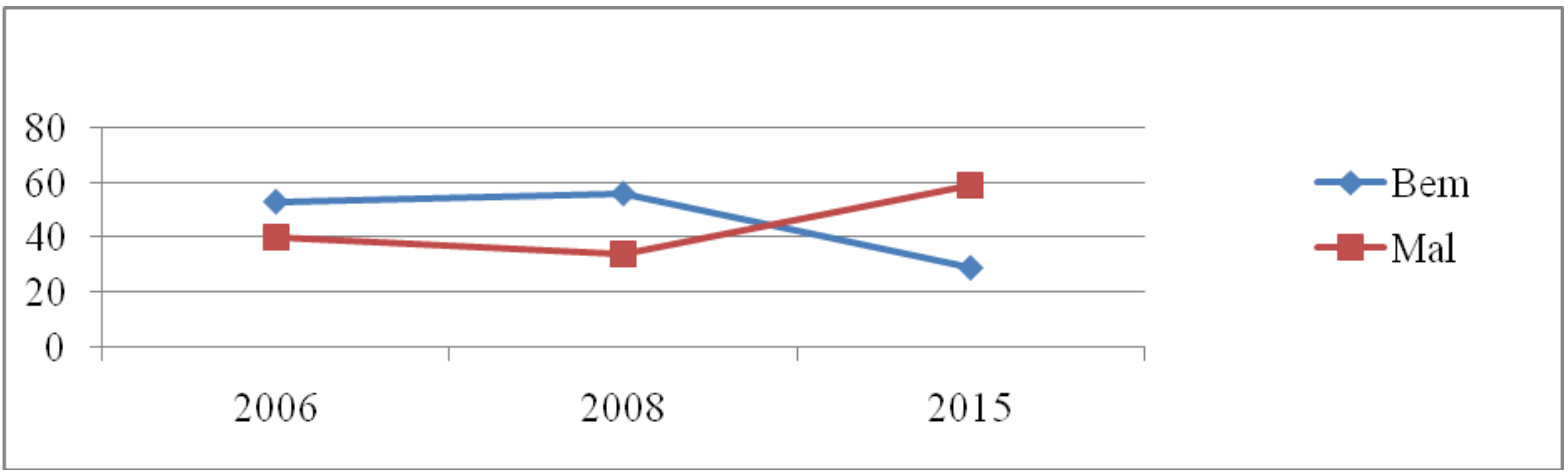

Fonte: Latinobarômetro (surveys 2006, 2008 e 2015).

*O gráfico mostra a direção das respostas em relação à avaliação do judiciário, onde os dados da coluna expressam a porcentagem e, as linhas, as séries temporais. Foram somados os dados das respostas "muito bem" com "bem" e "mal" com "muito mal" criando assim apenas dois vetores. Sobre essa questão o Latinobarômetro não dispõe de dados referentes a 2016.

O gráfico 7, da série temporal que vai até 2015, nos revela o aumento na insatisfação com os principais serviços públicos como educação $74 \%$, hospitais $85 \%$ e transporte públicos $70 \%$, além da polícia $76 \%$, e também destaca avaliações subjetivas como as do gráfico 8 , sentimento de insegurança quanto à proteção contra o crime $82 \%$, o meio ambiente $68 \%$ e a seguridade social $79 \%$. 
Campos Neutrais - Revista Latino-Americana de Relações Internacionais Vol. 1 No 1, Janeiro - Abril de 2019

\section{Gráfico 7}

Insatisfação com os serviços públicos - dimensões objetivas*

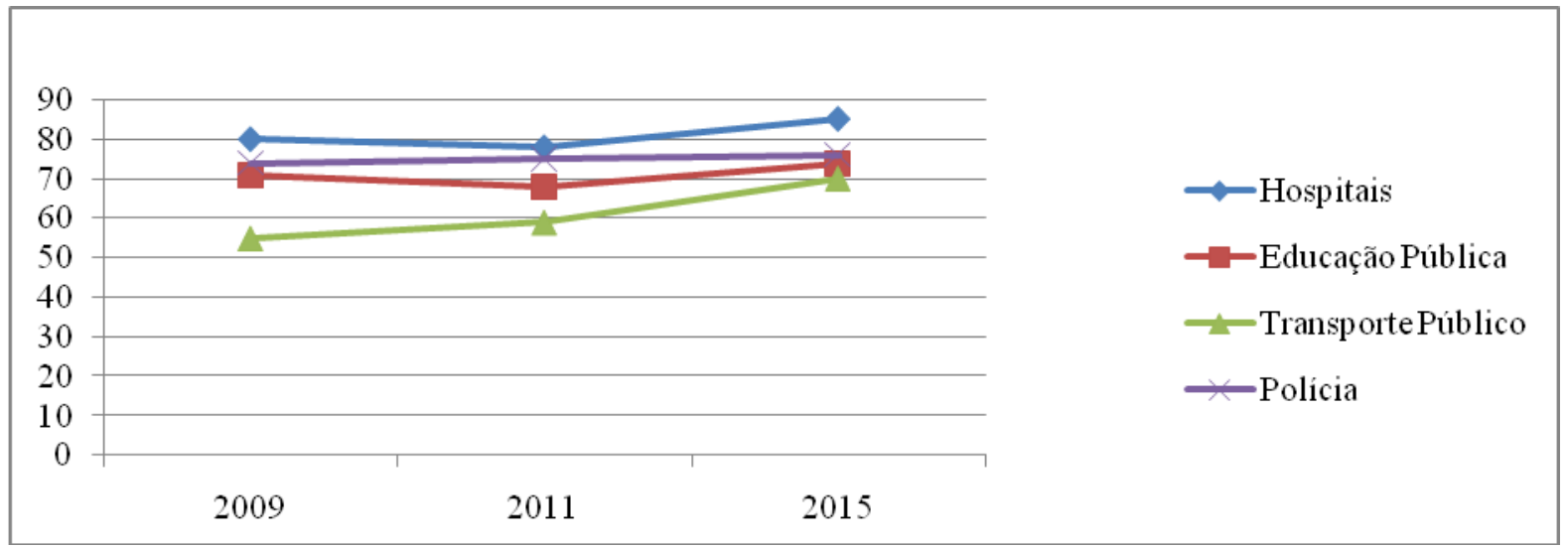

Fonte: Latinobarômetro(surveys 2009, 2011 e 2015).

*O gráfico mostra a direção das respostas na dimensão objetiva em relação à insatisfação com os serviços públicos como: hospitais, educação pública, transporte público e polícia (aspectos objetivos). Nesse caso, somamos os dados dos"insatisfeitos" com "muito insatisfeitos", criando um só vetor para cada serviço avaliado.

\section{Gráfico 8}

Insatisfação com os serviços públicos - dimensões subjetivas*

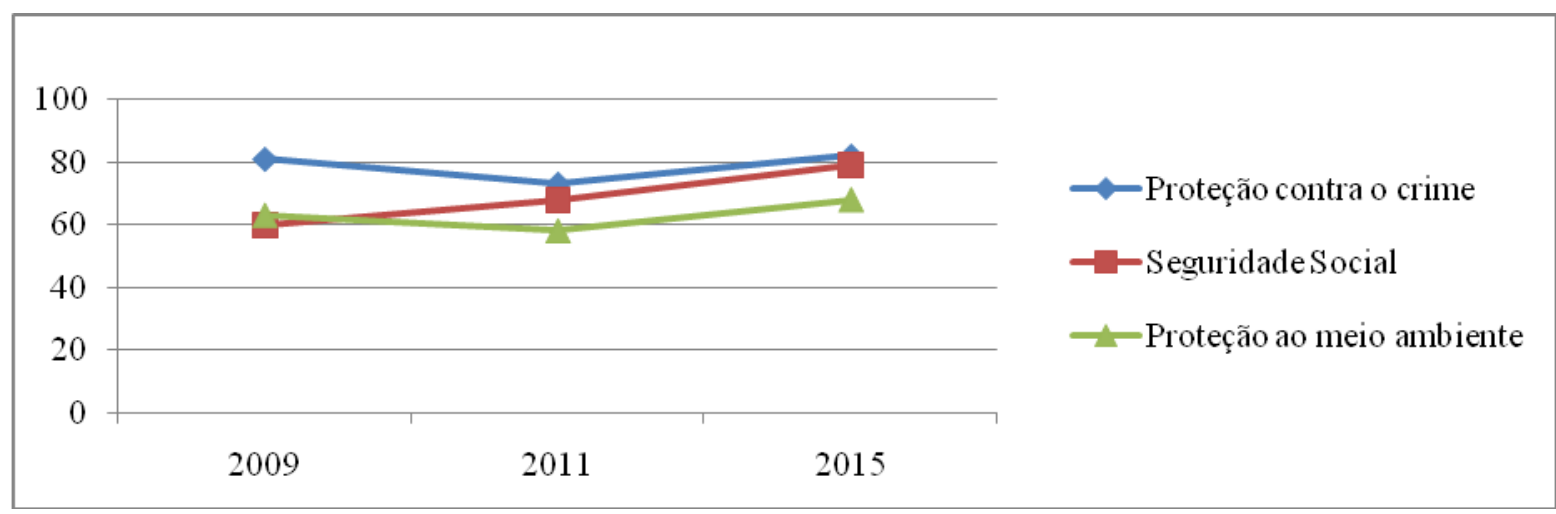

Fonte: Latinobarômetro (surveys 2009, 2011 e 2015).

*O gráfico mostra a direção das respostas na dimensão subjetiva em relação ao sentimento de insegurança quanto à proteção contra o crime, meio ambiente e seguridade social. Foram somamos os dados das respostas "pouco garantido" com "nada garantido". Os dados da coluna expressam porcentagens enquanto os da linha a série temporal.

O gráfico 9 nos mostra a percepção dos entrevistados com relação ao tema da corrupção. Quando perguntados se havia progresso em reduzir a corrupção nas instituições nos últimos dois anos, 74\% responderam que pouco ou nada havia sido feito nesse sentido em 2015. Em relação a se o entrevistado ou algum familiar sabia de algum caso de corrupção nos últimos doze meses, 70\% responderam que sim em 2015. Outra questão tratada neste gráfico é a da transparência do Governo, para os 
Campos Neutrais - Revista Latino-Americana de Relações Internacionais

Vol. 1 No 1, Janeiro - Abril de 2019

entrevistados, 78\% acreditam que o Governo é "pouco" ou "nada transparente" em 2015 .

\section{Gráfico 9}

Percepção da corrupção e transparência do Governo*

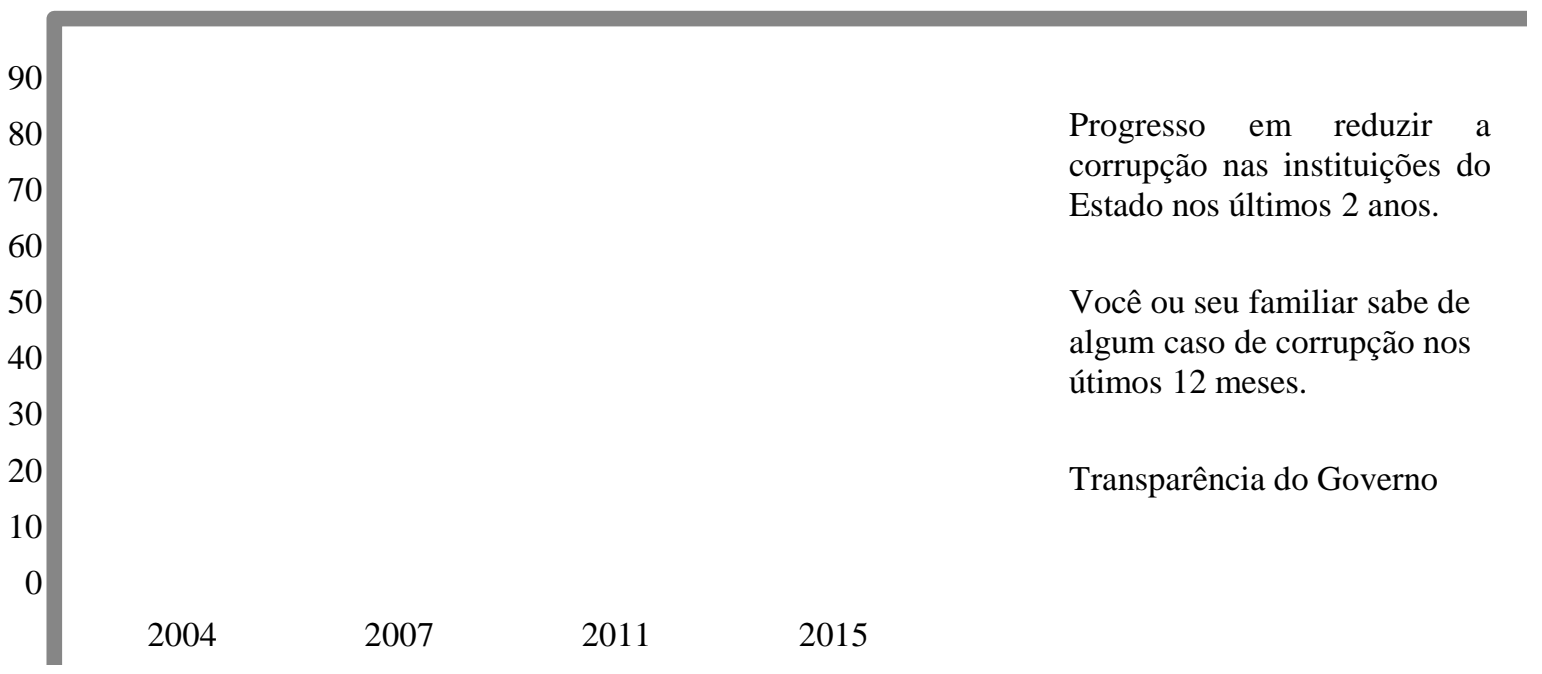

Fonte: Latinobarômetro(surveys 2004, 2007, 2011 e 2015).

*O gráfico mostra a direção das respostas em relação à percepção da corrupção e transparência do Governo, onde os dados da coluna expressam a porcentagem e, as linhas, a série temporal. Para avaliar o progresso em reduzir a corrupção nas instituições do Estado nos últimos dois anos somamos os dados das respostas "pouco" com "nada". Para a questão que avalia o conhecimento de casos de corrupção nos últimos doze meses usamos somente os dados dos entrevistados que responderam "sim". Para a avaliação da transparência do Governo foram somados os dados das respostas "pouco transparente" com "nada transparente".

E por fim, a tabela 1 com dados do World Values Survey (ondas 1989-1993, 2005-2009 e 2010-2014) busca analisar a mudança nos valores de emancipação do brasileiro ao longo do tempo. Podemos perceber que na primeira onda, 22\% dos brasileiros apresentavam valores de emancipação entre 0.2 e 0.3 , enquanto que apenas $11 \%$ estavam entre 0.5 e 0.6. Já na terceira onda analisada, apenas $9 \%$ dos brasileiros apresentavam valores emancipatórios entre 0.2 e 0.3 , enquanto que $22 \%$ já apresentavam valores de emancipação entre 0.5 e o.6. 
Campos Neutrais - Revista Latino-Americana de Relações Internacionais

Vol. 1 No 1, Janeiro - Abril de 2019

Tabela 1

Valores Pós-Materialistas

\begin{tabular}{|c|c|c|c|}
\hline \multirow{2}{*}{ Valores Emancipadores } & \multicolumn{3}{|c|}{ BRASIL } \\
\hline & $1989-1993$ & 2005-2009 & 2010-2014 \\
\hline $0-0.1$ & - & O\% & O\% \\
\hline $0.1-0.2$ & $13 \%$ & $4 \%$ & $2 \%$ \\
\hline $0.2-0.3$ & $22 \%$ & $13 \%$ & $9 \%$ \\
\hline $0.3-0.4$ & $25 \%$ & $24 \%$ & $21 \%$ \\
\hline $0.4-0.5$ & $\mathbf{2 0} \%$ & $25 \%$ & $\mathbf{2 8 \%}$ \\
\hline $0.5-0.6$ & $11 \%$ & $18 \%$ & $22 \%$ \\
\hline $0.6-0.7$ & $5 \%$ & $11 \%$ & $12 \%$ \\
\hline $0.7-0.8$ & $2 \%$ & $3 \%$ & $4 \%$ \\
\hline $0.8-0.9$ & $1 \%$ & $1 \%$ & $1 \%$ \\
\hline $0.9-1$ & $\mathrm{O} \%$ & o\% & $\mathrm{O} \%$ \\
\hline Ausência & $2 \%$ & O\% & $1 \%$ \\
\hline Base de dados de média & 1,755 & 1,496 & 1,478 \\
\hline Significar & 0.4 & 0.4 & 0.5 \\
\hline Desvio Padrão & 0.15 & 0.15 & 0.14 \\
\hline (n) & 1,782 & 1,500 & 1,486 \\
\hline
\end{tabular}

Fonte: World ValuesSurvey (ondas 1989-1993, 2005-2009 e 2010-2014) para o Brasil. Grifo nosso.

\section{Conclusões Preliminares}

O objetivo primeiro deste trabalho foi o de trazer para discussão o fenômeno existente, tanto em democracias consolidadas como em democracias da terceira onda, da baixa confiança institucional. Nossa hipótese de trabalho pretendeu confrontar a crescente adesão à democracia, enquanto princípios e valores, com a satisfação que o regime tem provocado nas percepções dos cidadãos brasileiros.Embora este trabalho precise ter seu escopo de análise ampliado para obter resultados mais satisfatórios, analises preliminar sugerem que estudos futuros devam apontar caminhos pelos quais os fenômenos da baixa confiança em instituições e baixa avaliação de desempenho e satisfação com a democracia sejam explicados por enfoques múltiplos que estejam além do mero desapontamento. Este trabalho sugeriu que a mudança nos valores, ainda que não nos moldes ocorridos nas democracias consolidadas, deve ser considerada uma variável implicativa importante. 
Campos Neutrais - Revista Latino-Americana de Relações Internacionais Vol. 1 No 1, Janeiro - Abril de 2019

Ao contrário do que afirma Fukuyama (2015, p.53), de que a legitimidade de muitas democracias dependeria menos da consolidação de suas instituições do que de sua capacidade de oferecer governança de alta qualidade, este trabalho procura mostrar que estas duas situações podem e devem estar concatenadas numa trajetória pela qual as instituições políticas constituam papéis centrais no processo de acessar a uma alta legitimidade do sistema político e consequentemente uma boa qualidade da democracia.

Apesar dos brasileiros aderirem cada vez mais à democracia, interiorizando valores como liberdade, igualdade e participação, menos eles encontram em instituições como os Partidos Políticos, Congresso Nacional e Justiça, as respostas para seus problemas. Reforçar o grau de confiança dos cidadãos nas instituições, consolidando-as, significa potencializar a capacidade do Estado para que, através delas, se projetem políticas públicas para melhorar a qualidade dos serviços públicos, e diminuir a corrupção. Nesse ponto, o sistema político se beneficiária com consequências importantes para o cidadão comum, a razão central de existência dessa engenharia.

A promoção de governança de alta qualidade pelo regime e a alta legitimidade do sistema político deve necessariamente convergir, portanto, pelo fortalecimento das instituições políticas.A capacidade do Estado e a mudança nos valores, esta última cada vez resiliente diante da acentuação do processo de globalização, são variáveis que devem ser incorporadas em trabalhos que tratem da legitimidade do sistema político. Nelas estarão grifados os papéis centrais que as diferentes culturas políticas desempenham na composição dos mais diferentes regimes políticos, e se serão satisfatórias ou instáveis para com os seus cidadãos.

\section{Referências}

ALMOND, Gabriel; VERBA, Sidney. The civic culture: political attitudes and democracy in Five nations. Princeton: Princeton University Press, 1966.

BAQUERO, Marcello. Democracia formal, cultura política informal e capital social no Brasil. Opinião Pública, Campinas, vol. 14, nº 2, p. 380-413, nov. 2008.

Qual democracia para a América Latina?:capital social e empoderamento são a resposta?. Porto Alegre: Editora da UFRGS, 2013. 
Campos Neutrais - Revista Latino-Americana de Relações Internacionais Vol. 1 No 1, Janeiro - Abril de 2019

CATTERBERG, G; MORENO, A. The individual bases of political trust: trends in new and established democracies. International Journal of Public Opinion Research, Oxford, 18(1): 31-48, 2006.

DAHL, Robert A. Poliarquia:participação e oposição. São Paulo: Edusp, 2012.

DIAMOND, Larry. Facing up to the democratic recession.Journal of

Democracy, vol. 26, $\mathrm{n}^{\mathrm{o}} 1,2015$.

EASTON, David. Uma teoria de análise política. Rio de Janeiro: Zahar, 1968.

FAORO, Raymundo. Os Donos do poder: formação do patronato político. São Paulo: Globo, 2012.

FUKUYAMA, Francis. Why democracy is performing so poorly?.Journal of Democracy, 26(1): 11-20, 2015.

HUnTIngton, Samuel P. A Ordem Política Nas Sociedades Em Mudança. São Paulo: Forense/EDUSP, 1975.

HUNTINGTON, Samuel P. Democracy's Third Wave. Journal of Democracy, vol. 2, $\mathrm{n}^{0}$ 2, Spring 1991.

INGLEHART, Ronald. Cultura e democracia. In: HARRISON, Lawrence E.; HUNTINGTON, Samuel P. (Orgs.). A Cultura importa. Rio de Janeiro: Record, 2002.

; Democratização em perspectiva global. Opinião Pública, Campinas, vol. I, julho/agosto, 1993, p. 09-67.

; WELZEL, Christian. Modernização, mudança cultural e democracia: e sequencia do desenvolvimento humano. São Paulo: Francis, 2009.

A Revolução Silenciosa na Europa: Mudança Intergeracional nas Sociedades Pós-Industriais. Revista de Sociologia e Política, Curitiba, v. 20, n. 43, p. 159-191, out. 2012.

LATINOBARÔMETRO. Disponível em: http://www.latinobarometro.org/lat.jsp. Acesso em: 05/04/2016.

LIPSET, Seymour Martin. O Homem político. Rio de Janeiro: Zahar, 1967.

MARKOFF, John. Waves of democracy: social movements and political change. Thousand Oaks, CA: Pine Forge Press, 1996.

MENEGUELLO, Rachel. Aspectos de desempenho democrático: estudo sobre a adesão à democracia e avaliação do regime. In: MOISÉS, José Álvaro. (Org.). Democracia e confiança: por que os cidadãos desconfiam das instituições públicas. São Paulo: Universidade de São Paulo, 2010. 
Campos Neutrais - Revista Latino-Americana de Relações Internacionais Vol. 1 No 1, Janeiro - Abril de 2019

As Bases do apoio ao regime democrático no Brasil. In: MOISÊS, José Álvaro; MENEGuello, Rachel. (Orgs). A Desconfiança política e os seus impactos na qualidade da democracia. São Paulo: Universidade de São Paulo, 2013.

MOISÉS, José Álvaro. Democracia e desconfiança das instituições democráticas. In: MOISÉS, José Álvaro. (Org.). Democracia e confiança: por que os cidadãos desconfiam das instituições públicas. São Paulo: Universidade de São Paulo, 2010.

; CARNEIRO G. P. Democracia, desconfiança política e insatisfação com o regime: o caso do Brasil. Opinião Pública, Campinas, v. 14, $n^{0}$ 1, 1-42, jun. 2008.

; MENEGUELLO, Rachel (Orgs). A Desconfiança política e os seus impactos na qualidade da democracia. São Paulo: Universidade de São Paulo, 2013.

NORRIS, Pippa. The Growth of critical citizens?. In: (ed.). Critical citizens: global support for democratic governance. New York: Oxford University, 1999.

Democratic deficit: critical citizens revisited. Spring: Cambridge University, 2011.

Making democratic governance work: the impact of regimes on prosperity, welfare and peace. New York: Cambridge University, 2012.

OFFE, Claus. How can we our fellow citizens?. In: Warren, M. (Ed.) Democracy and trust. Cambridge: Cambridge University Press, 1999.

PASE, Hemerson; SANTOS, E. R. Capital Social e Desenvolvimento no Rio Grande do Sul. In: BAQUERO, Marcello; CREMONESE, Dejalma (Org.) Desenvolvimento regional: democracia local e capital social. Ijuí: Unijuí, 2008, p. 41-68.

PRZEWORSKI, Adam. Como e Onde se Bloqueiam as Transições Para a Democracia. In: MOISÉS, José Álvares; ALBUQUERQUE, José Augusto Guilhon (Orgs.). Dilemas da Consolidação da Democracia. Rio de Janeiro: Paz e Terra, 1989. RIBEIRO, Ednaldo Aparecido. Confiança política na América Latina: evolução recente e determinantes individuais. Revista de Sociologia Política, Curitiba, 19(39): 167-182, jun. 2011.

SANTOS, Everton Rodrigo. Poder e dominação no Brasil: a Escola Superior de Guerra (1974-1989). Porto Alegre: Sulina; Novo Hamburgo: Feevale, 2010. 
Campos Neutrais - Revista Latino-Americana de Relações Internacionais Vol. 1 No 1, Janeiro - Abril de 2019

SANTOS, Everton Rodrigo. Democracia e desenvolvimento: desafios da sociedade gaúcha. Ijuí: Unijuí, 2013.

SCHWARTZMAN, Simon. Bases do autoritarismo brasileiro. Rio de Janeiro: Campus, 1982.

Recebido em Novembro de 2018 Aprovado em Dezembro de 2018 